\title{
THE EFFICACY OF LASER GLAZING ON SURFACE ROUGHNESS AND STRUCTURE OF ALL-CERAMIC VENEERS
}

\author{
Sara Salah Hegazy* , Azza Mohamed Abdel Zaher Hashem** and Shaymaa Ibrahim Habib***
}

\begin{abstract}
Aim of the study : This study was designed to set up proper laser parameters including laser type, power intensity and time of application for glazing of a particular glass-ceramic.

The effect of laser glazing of the glass-ceramics on structural and roughness was investigated, evaluated and compared with the recommended glazing technique.

Material and Methods :The materials used in this study were two commercially available lithium disilicate ceramics, fabricated by two different techniques: conventional lost wax (Injectable heat - pressed) and machinable Computer Aided Design / Computer Aided Manufacturing (CAD/ CAM) techniques. A total of 50 ceramic samples in the form of discs $(5 \mathrm{~mm}$ diameter and $2 \mathrm{~mm}$ thickness). For CAD/ CAM samples, a total of 50 discs were done sequentiallyin the Cerec 3 CPUacquisition unit. Two glazing techniques were adopted to the studied ceramic samples namely; conventional glazing and laser glazing. For each material subjected to the different glazing protocols structural Analysis, Surface Roughness was measured before and after glazing using white light Profilometry.
\end{abstract}

Results: Results of surface roughness (Ra) of the two investigated materials; IPS E-max press and IPS E-max CAD using two different surface treatments; conventional glazing and laser glazing in comparison to the control group are presented. For of $\mathrm{M}_{1}$; IPS E-max press material ANOVA results showed that the control group had the significantly highest surface roughness followed by laser glazing, while the conventional glazing showed the significantly lowest mean surface roughness ( $\mathrm{p}<0.001)$. Regarding M2; IPS E-max CAD material no significantly difference was found between conventional glazing and laser glazing.

Conclusions:Within the limitations of the current study, the following conclusions were drawn: 1. Conventional glazing can be considered as the most reliable glazing technique as regard surface roughness. 2. Laser glazing with high power density increased the surface roughness of lithium silicate based ceramics.

* B.D.S 2005 (Cairo University), Demonstrator of Dental Materials , Biomaterial Department

** Professor of Dental Materials, Biomaterials Department, Faculty of Oral and Dental Medicine, Cairo University *** Lecturer of Dental Materials, Biomaterials Department, Faculty of Oral and Dental Medicine, Cairo University 


\section{INTRODUCTION}

Throughout dental history, dentists have continually searched for the ideal restorative material. Dental ceramics are commonly used to serve this purpose because they are biocompatible and semitransparent to create esthetic restorations. As well, ceramics can tolerate heavy loads and have a thermal expansion coefficient suitable for dental structure. ${ }^{(1,2)}$

The surface of all dental restorative materials should be smooth to allow biologic compatibility, proper function and better esthetics. The rough surfaces can accumulate stains, plaque, decrease the flexural strength of a material ${ }^{(3)}$.

Thus, proper surface finishing is essential to prevent some of these problems by providing a smooth surface. There are three techniques available to obtain a correct finish for the dental ceramic: self glazing (intrinsic glazing), traditional glazing (extrinsic glazing), and mechanical surface polishing.

Recently, there is an increased demand of laser in material processing that can be attributed to several unique advantages of laser. These advantages are; improved product quality, reduced processing cost, non-contact processing, elimination of finishing operation and minimum heat affected zone.

Over the last two decades, the use of laser systems for the treatment of ceramic, in particular surface glazing, has received increased interest. According to the current literature, there is no optimum wavelength or laser power for ceramic glazing. Thus, different interaction of applications time and power intensities of laser beam could lead to various ceramic surface effects that need further investigation

\section{MATERIAL AND METHODS}

\section{Materials}

The materials used in this study were two commercially available lithium disilicate ceramics, fabricated by two different techniques: conventional lost wax (Injectable heat - pressed) and machinable Computer Aided Design / Computer Aided Manufacturing (CAD/CAM) techniques.

\section{Materials used in the study:}

Material $1\left(\mathbf{M}_{1}\right)$ IPS E-max press

Material $2\left(\mathbf{M}_{2}\right)$ IPS E-max CAD

\section{Methods:}

A total number of 100 samples were used in the current study, half of which were assigned to each material $(M) ;(n=50 / M)$.

\section{Construction of Samples}

\section{For Pressable Ceramic Samples:}

A total of 50 ceramic samples in the form of discs ( $5 \mathrm{~mm}$ diameter and $2 \mathrm{~mm}$ thickness) were fabricated using specially designed stainless steel mold while for CAD /CAM Samples:

A total of 50 discs were done sequentially in the Cerec 3 CPU acquisition unit,

Grouping of Samples According to the Glazing Technique (G):

Two glazing techniques were adopted to the studied ceramic samples namely; conventional glazing and laser glazing.

Conventional glazing $\left(\mathbf{G}_{\mathbf{1}}\right)$ for Both materials $\left(\mathrm{M}_{1}\right.$ and $\mathrm{M}_{2}$ ) according to the manufacturer's instructions.

Laser glazing $\left(\mathbf{G}_{2}\right)$ Both materials $\left(\mathrm{M}_{1}\right.$ and $\left.\mathrm{M}_{2}\right)$ were subjected to laser glazing using $\mathrm{CO}_{2}$ laser device (Nova pulse Lx-2o SP, Lwxar, Bothell, wash) in the continuous mode (15 msec. 2HZ),). The laser 
parameters used were 20 watt Power, 200 J Energy and 10 seconds application time repeated three times with a resting period of 10 seconds between each application.

\section{Structural Analysis}

X-Ray diffraction (XRD) analysis was conducted to identify the crystalline phases of the glass ceramic samples before and after glazing using X-Ray Diffractometer

XRD analysis was conducted with $\mathrm{Cu} \mathrm{k}_{\alpha 1}$ ray of wave length $1.54056 \AA$ and with $2 \theta$ angle ranging from $10^{\circ}-70^{\circ}$ at an angular sweeping rate of $0.01^{\circ}$. Then, the characteristics peaks of each phase were matched with the data compiled in the joint committee of powder diffraction standards (JCPDS) database.

\section{Surface Roughness:}

Five samples for each material and for each glazing technique were prepared for roughness measurement before and after glazing using white light Profilometry

The Profilometer is a general purpose surface optical profiler that measures the microstructure and topography of surfaces in three dimensions.

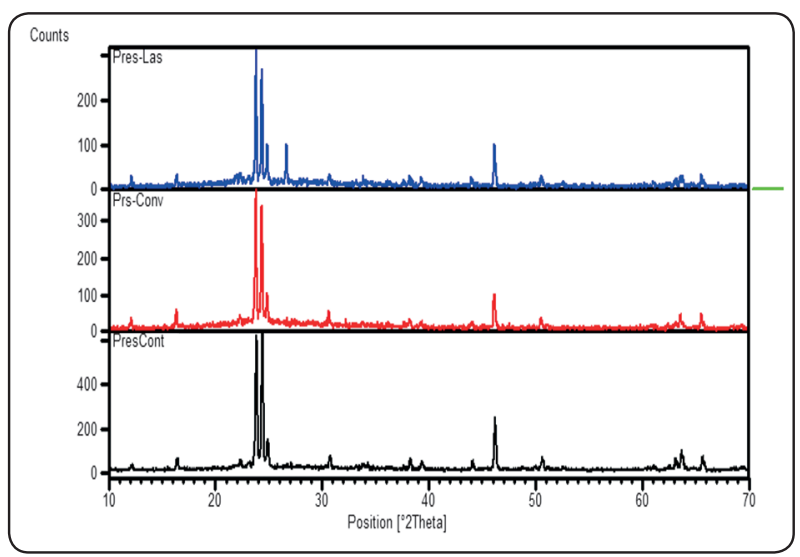

Fig. (1) X-ray diffraction spectral curves for M1 (E-Max press materials) control, conventional and laser groups

\section{RESULTS}

\section{Results of X-Ray Diffractometer Analysis:}

X-ray diffraction spectral curves for the investigated materials; M1 and M2, after conventional and laser glazing in comparison to the control groups are presented in Figures 1,2

Regarding $\mathrm{M}_{1}$; IPS E-max press, results showed that all major and minor peaks of the control group matched with that of the JCPDs card no 82-2396 for lithium silicate. Major peaks were detected at $2 \theta=24.3,23.8$ and 46.19 which corresponded to d-spacing $=3.64,3.73$ and 1.96 respectively. While, minor peaks was detected at $2 \theta=24.86,30.68$ and 63.6 which corresponded to d-spacing $=3.57,2.91$ and 1.46 respectively.

After conventional glazing for heat press materials, results showed remarkable decrease in the intensity of the peaks which appeared at $2 \theta=24.29$, 24.83 and 46.09 that corresponded to d- spacing $=3.66,3.58$ and 1.96 respectively. Similarly, after laser glazing, results showed decrease in the intensity at $2 \theta=24.33$ and 46.12 that correspond to d-spacing $=3.65$ and 1.96 respectively. Meanwhile new peak appeared at $2 \theta=26.64$ that corresponded to $\mathrm{d}$ - spacing $=3.34$.

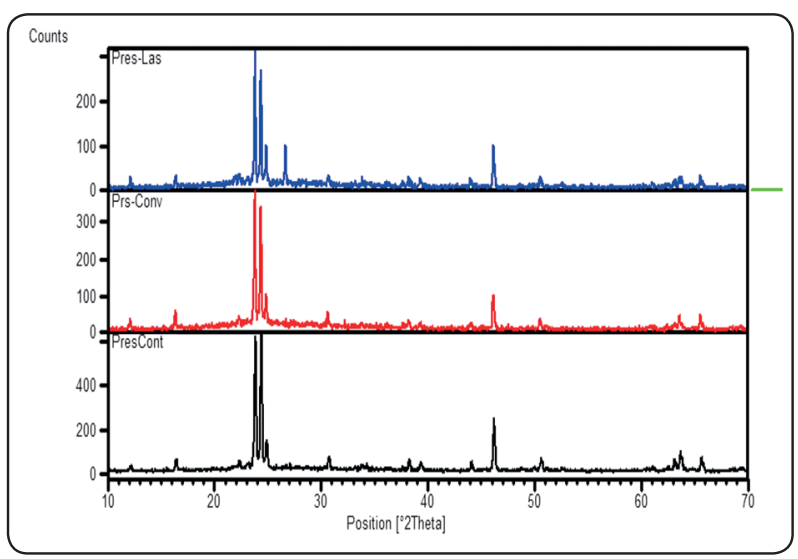

Fig. (2) X-ray diffraction spectral curves for M2 (E-Max CAD materials) control, conventional and laser groups 
Regarding M2; IPS E-max CAD, results of XRD for the control group showed that all major and minor peaks also matched with that of the JCPDs card no 82-2396 for lithium silicate. Major peaks were detected at $2 \theta=24.9,23.89,24.45$ and 37.73 which corresponded to d-spacing $=3.56,3.72,3.63$ and 2.38 respectively.

After conventional glazing of CAD/CAM material, results showed no changes in the intensity of the peaks which appeared at $2 \theta=24.8,23.8,24.38$ and 37.63 which corresponded to d-spacing $=3.64$, $3.73,3.64$ and 2.38 respectively.

After laser glazing result showed no remarkable changes at $2 \theta=24.8,23.7,24.35$ and 37.63 which corresponded to d-spacing $=3.57,3.73,3.65$ and 2.38 respectively.

\section{II- Results of Surface Roughness}

Results of surface roughness (Ra) of the two investigated materials; IPS E-max press and IPS E-max CAD using two different surface treatments; conventional glazing and laser glazing in comparison to the control group are presented in Table (1) and graphically illustrated in Figure (3)

Results showed that the mean surface roughness of $\mathrm{M}_{1}$; IPS E-max press material were $1.60 \pm 0.12 \mu$, $0.35 \pm 0.10 \mu$ and $1.13 \pm 0.15 \mu$ for the control group, conventional glazing and laser glazing respectively. ANOVA results showed that the control group had the significantly highest surface roughness followed by laser glazing, while the conventional glazing showed the significantly lowest mean surface roughness $(\mathrm{p}<0.001)$.

Regarding M2; IPS E-max CAD material, the mean surface roughness were $1.48 \pm 0.24 \mu, 0.58$ $\pm 0.06 \mu$ and $0.77 \pm 0.15 \mu$ for the control group, conventional glazing and laser glazing respectively. Control group showed the statistically highest surface roughness $(1.48 \pm 0.24 \mu)$. However, no significantly difference was found between conventional glazing and laser glazing.

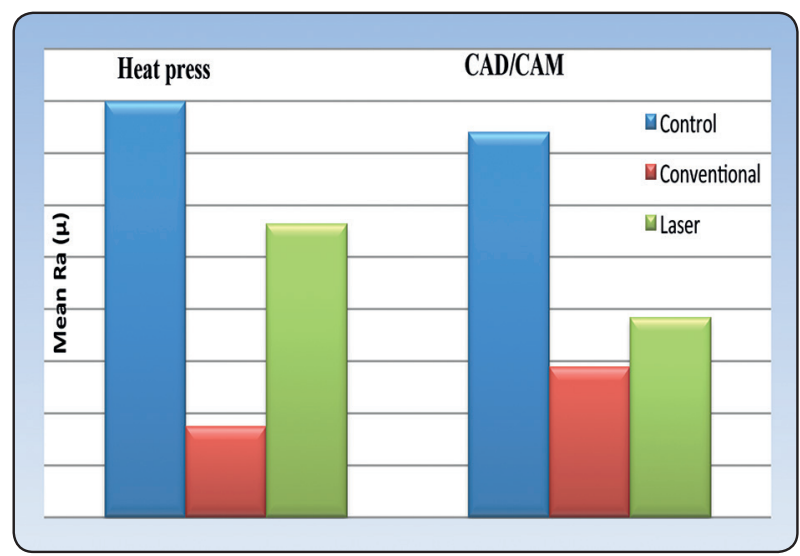

Fig. (3): Mean surface roughness $(\mu)$ of the two investigated materials using two different glazing techniques in comparison to the control group.

Table (1): Mean surface roughness $(\mu)$ and standard deviation values for the two investigated materials with two different surface treatments.

\begin{tabular}{|c|c|c|c|c|c|c|c|}
\hline \multirow{2}{*}{$\begin{array}{c}\text { Surface treatment } \\
\text { Technique }\end{array}$} & \multicolumn{2}{|c|}{ Control } & \multicolumn{2}{c|}{$\begin{array}{c}\text { Conventional } \\
\text { Glazing (G1) }\end{array}$} & \multicolumn{2}{c|}{ Laser Glazing (G2) } & $P$-value \\
\cline { 2 - 8 } & Mean & SD & Mean & SD & Mean & SD \\
\hline Heat press $\left(\mathbf{M}_{1}\right)$ & $1.60^{\mathrm{a}}$ & 0.12 & $0.35^{\mathrm{c}}$ & 0.10 & $1.13^{\mathrm{b}}$ & 0.15 & $<0.001^{*}$ \\
\hline CAD-CAM $\left(\mathbf{M}_{2}\right)$ & $1.48^{\mathrm{a}}$ & 0.24 & $0.58^{\mathrm{b}}$ & 0.06 & $0.77^{\mathrm{b}}$ & 0.15 & $<0.001^{*}$ \\
\hline
\end{tabular}

\footnotetext{
* Significant at $P \leq 0.05$, different superscripts in the same row are statistically significantly different
} 


\section{DISCUSSION}

The use of ceramic permits a great opening of applications inside of the modern dentistry, due to its biocompatibility and capacity to reproduce extremely pleasant esthetic aspects in the oral rehabilitation. Therefore, the demand for achieving superb esthetic quality has led to an increase in the development of new materials and new technologies. Improvements in ceramic technology have taken the form of novel processing techniques. This together with patient demands for superior esthetic has led to a renewed interest in all-ceramic technology.

Although dental porcelains almost meet the needs expected from a restorative material, they have an important disadvantage. These materials are brittle and have very low fracture toughness $\left(\sim 1.0 \mathrm{MPa} \mathrm{m}{ }^{1 / 2}\right)^{(4)}$, which limit their applications.

The limited fracture toughness is related to the porcelain's failure mechanism. Stress concentrations around microstructural defects will eventually lead to crack propagation and catastrophic failure. . $^{(4,5,6)}$ Due to the low fracture toughness of porcelains, even low stress levels concentrated around crack tip can result in crack propagation. ${ }^{(6)}$ Therefore, the presence of pores and flaws within the porcelain microstructure has a significant influence on clinical lifetime of the restoration.

In order to reduce the number of flaws and surface roughness caused by processing or grinding, a porcelain restoration can be submitted to glazing ${ }^{(7,8,9)}$ or polishing procedures. ${ }^{(9,10)}$

The glaze cycle may be carried out with or without the application of a new glass powder (the so-called overglaze and auto-glaze, respectively). Both approaches produce a smooth surface with significantly less flaws and higher gloss level. ${ }^{(11,12)}$

It seemed to be important to investigate newly developed fabrication technologies. Thus, two materials based on the technique of fabrication have received much interest; IPS E-max Press and IPS E-max CAD both based on lithium disilicate.
However, this material comprises detailed and technique sensitive steps that consumed many hours in the dental lab. This urged the manufacturer recently to introduce the new IPS E-max CAD to be used with the novel Cerec in Lab which allowed an easy, reliable and rapid fabrication for all-ceramic dental restorations with high mechanical strength and a good biocompatibility.

Many studies ${ }^{(8,9)}$ suggested that glazed porcelain provided the smoothest and most dense surface. Other than smoothness, the hardness and discoloration of the porcelain have been also points of interest. It has been proved that conventional methods for the surface glazing of dental ceramic materials were not capable of creating a smooth surface without microcracks. Meanwhile, it was suggested that laser glazing of ceramic surfaces inhibited the formation of microcracks leading to greater mechanical resistance of the ceramic.

Recently, an alternative heat treatment using laser technology was proposed for the glazing cycle of porcelain. ${ }^{(13)}$ It was claimed that laser glazing resulted in specimens with fewer superficial defects and smoother surface when compared to specimens glazed in a conventional furnace. In addition, laser glazing shortened the time needed to obtain smooth surfaces.

This technical procedure provides a remelting and subsequent solidification of the surface, resulting on a dense top layer with a new microstructure. Moreover, Binns (1983) ${ }^{(14)}$ found that the melted superficial layer of ceramic material has a lower thermal expansion coefficient than interior. This would place the outer surface in compression when cooled. The compressive stress state would diminish the local tensile stress produced from applied loading at surface flaws, thereby necessitating the need for increased applied loading to initiate flaw propagation from the external surface.

In the current study, the laser treatment was achieved by using $\mathrm{CO}_{2}$ laser beam of diameter $0.4 \mathrm{~mm}$ 
and $10.6 \mu \mathrm{m}$ wavelength that was directed to the center of the ceramic disc. The beam was delivered in a continuous mode through an articulating arm while using 20 watt Power and 10 seconds application time. This was repeated three times with a resting period of 10 seconds between each application. A resting period of 10 seconds between each shot was made to reduce the cumulative thermal effect of the laser beam on the samples surface and preventing surface melting of the ceramic. In addition, the used laser parameter (20watt, continuous mode) was selected after different pilot studies with different laser power and application time (10 watt) and (30 watt) in continuous and pulsed mode for 10 and 20 seconds. The pilot studies showed that using low power settings produced nearly no changes in the surface roughness measurements. Meanwhile, high power setting caused extensive charring of the ceramic samples. reported that $\mathrm{CO}_{2}$ laser revealed a distinct surface alterations to zirconia surface at various laser parameters. Results showed excessive melting of the ceramic surface when 20 watt Power for 30 seconds without resting periods was used. They concluded that by using these parameters, the surface destruction that might be in the form of cracks or excessive melting was prevented.

$\mathrm{CO}_{2}$ laser was reported to be well suited for the treatment of porcelain materials because its emission wavelength is almost totally absorbed by porcelain. However, the effect of laser glazing of ceramic materials on their properties differs according to variation in energy density of the $\mathrm{CO}_{2}$ laser and power setting.

It should be mentioned that selection of $\mathrm{CO}_{2}$ laser type was based on the previous findings ${ }^{(15,16,17,18)}$ who stated that $\mathrm{CO}_{2}$ is suited for the treatment of the surface of materials in relatively safe and easy means. This could be attributed to that $\mathrm{CO}_{2}$ laser beam did not penetrate the ceramic surface as other laser types that might cause uncontrolled microstructural changes.
X-ray diffraction was performed to evaluate internal structure of the studied specimens. The diffraction patterns of porcelain specimens demonstrated sharp well-defined peaks which indicated that both materials having predominantly crystalline structure with very few broad bands which corresponded to the amorphous glassy phase. However, the spectral curves of both materials; E-max CAD and E-max press showed that glazing whether conventional or laser glazing changed only the intensities of peaks rather than their position. This indicated that glazing had no significant effect on the internal microstructure of porcelain and it was just a surface treatment.

In all X-ray diffraction patterns of porcelain samples, the measured peak positions belonged to peaks of lithium disilicate which was the main crystal phase with orthorhombic lattice structure. The peaks of the control groups of both investigated materials, demonstrated a remarkable decrease in their intensities after laser treatment. This could be explained by the thermal effect of laser in providing energy, sufficient to make slight changes in the atomic positions or causing slight overlapping of some atomic planes over each others. ${ }^{(19)}$

According to roughness results, ceramic samples of heat pressed material showed that conventional group had the lowest roughness, while for CAD/ CAM material, no significant difference was found between conventional and laser groups. The increase in surface roughness with laser group could be attributed to the effect of the laser energy discharge that promoted a distinct surface changes. These changes were in the form of pores, caused by material removal by the laser, and elevations caused by fusing and melting of the most superficial ceramic layer and its re-solidification. Besides, microcracks formation, as shown in the SE micrographs, as well as the increase in crystal size with laser irradiation.

This result was in agreement with Akin, et al., $(2011)^{(20)}$ and Cavalcanti, et al. $(2009 a)^{(21)}$ who irradiated ceramic surface with laser and 
found increased surface roughness and surface irregularities compared to the untreated specimens. Additionally, Stiibinger et al., (2008) $)^{(17)}$ studied the effect of laser on ceramic surface. They applied $\mathrm{CO}_{2}$ Laser manually on the discs in circular motion to expose the entire surface. Results showed increased surface roughness and cracks formation. Though, in this paper the author applied the $\mathrm{CO}_{2}$ laser manually on the disc in a circular motion in order to expose the entire surface. Meanwhile, in the current study, $\mathrm{CO}_{2}$ Laser was selected as an alternative to oven glaze as a surface treatment after chairside adjustment when considering roughness and color parameter.

\section{CONCLUSIONS}

Within the limitations of the current study, the following conclusions were drawn:

1. Conventional glazing can be considered as the most reliable glazing technique as regard surface roughness.

2. Laser glazing with high power density increased the surface roughness of lithium silicate based ceramics.

\section{REFERENCES}

1. Jacobi R, Shillinburg HT Jr, Duncanson MG: A comparison of the abrasiveness of six ceramic surfaces and gold. $\mathrm{J}$ Prosthet Dent 1991; 66(3):303-39.

2. Rosenblum MA, Schulman A: A review of all-ceramic restorations. J Am Dent Assoc1997; 128(3):297-307.

3. Bessing C, Wiktorsson.: A comparison of two different methods of polishing porcelain.Scand J Dent Res1983; 91(6):482-487.

4. Raigrodski AJ; Chiche GJ (2001) The safety and efficacy of anterior ceramic fixed partial dentures: A Review Of The Literature. J Prosthet. Dent. 86(5):520-525.

5. Gonzaga CC; Okada CY; Cesar PF; Miranda WG Jr; Yoshimura HN (2009) Effect of processing induced particle alignment on the fracture toughness and fracture behavior of multiphase dental ceramics. Dent. Mater 25(11):1293-130.
6. MorenaR; Lockwood PE; Fairhurst CW.: Fracture toughness of commercial dental porcelains. Dent Mater 1986. 2(2):58-62

7. Griggs JA; Thompson JY; Anusavice KJ.: Effects of flaw size and auto glaze treatment on porcelain strength. J Dent Res. 1996; 75(6):1414-17

8. Baharav H; Laufer BZ; Pilo R; Cardash HS (1999) Effect of glaze thickness on the fracture toughness and hardness of alumina- reinforced porcelain. J Prosthet Dent. 1999; 81(5):515-519.

9. Al-Wahadni A, Martin DM (1998) Glazing and finishing dental porcelain: a literature review. J Am Dent Assoc. 1998; 64(8):580-583

10. Yuzugullu B, Celik C, Erkut S, Ozcelik TB (2009) The effects of extraoralporcelain polishing sequences on surface roughness and color of feldspathicporcelain. Int J Prosthodont, 2009; 22(5):472-475

11. Motro PF; Kursoglu P, Kazazoglu E (2012) Effects of different surface treatments on stainability of ceramics. J Prosthet. Dent. 2012; 108(4):231-7.

12. Yilmaz K; Ozkan P (2010) The methods for the generation of smoothness in dental ceramics. Compend Contin Educ Dent. 2010; 31(1):30-2; 34; 36-8 passim; quiz 42; 44.

13. Prasad S, Monaco EA Jr; Kim H, Davis EL; Brewer JD (2009) Comparison of porcelain surface and flexural strength obtained by microwave and conventional oven glazing. J.Prosthet Dent. 2009; 101(1):20-28

14. Binns DB. The chemical and physical properties of dental porcelain. In: Dental ceramics,proceedings of the first international symposium on ceramics. McLean JW, editor. Chicago: Quintessence Publishing Co., Inc. 1983; 41-82.

15. Ersu, B.; Yuaugullu, B.; Euya, Y.A. \& Canay, S. (2009). Surface roughness and bond strength of glass-infiltrated alumina-ceramics prepared using various surface treatments. Journal of Dentistry 2009; 37, 848-856.

16. Akova, T.; Yoldas, O.; Toroglu, M3. Uysal, H. (2005). Porcelain surface treatment by laser for bracket-porcelain bonding. Amenam Journal of Orthodont. \& Dentofacial Ortho., 2005; 128, 630-637.

17. Stübinger, S.; Homann, F.; Etter, C.; Miskiewicz, M.; Wieland, M. Sader, R. (2008). Effect of Er:YAGr, CO2 and diode laser irradiation on surface properties of zirconia endosseous dental implants. 2008; 40(3) 223-228. 
18. Cavalcanti, AN.; Pilecjki, P.; Foxton, RM; Watson, TF.; Oliveira, MT.; Gianmni.M. Marchi,GM. (2009b). Evaluation of the surface roughness and morphologic features of Y-TZP ceramics after different surface treatments. Photomedicme and Laser Surgery, 2009b; 27(3), 473-479.

19. Noda, M.; Okuda, Y.; Tsuruki, J.; Minesaki, Y.; Tekenouchi, Y. Ban S. (2010). Surface damages of zirconia by Nd:YAG dental laser irradiation. Dental Materials Journal, 2010; 29(5), 536-541.
20. Akin, H.; Tugutr F.; Emine, A.G.; Guney, U. Mutaf, B.: Effect of Er:YAG laser application on the shear bond strength and micro leakage between resin cements and Y-TZP ceramics. Lasers in Medical Science, 2011; 21. 15-6.

21. Cavalcanti,AN.; Foxton, Watson,; Qliveifa, MT.; Giannim, M. Marc hi, GM.(2009a). Bond strength of resin cements to azirconia ceramic with different surfacetreatments. Oper. Dent. 2009; 34(3) 280-287. 